Int. J. Dev. Biol. 55: 327-334 (2011)

doi: 10.1387/ijdb.103270jy

\title{
Dynamic expression of manganese superoxide dismutase during mouse embryonic organogenesis
}

\author{
JUNG-MINYON¹, IN-JEOUNG BAEK², BEOM JUN LEE¹, YOUNG WONYUN¹ and SANG-YOON NAM*,1 \\ ${ }^{1}$ College of Veterinary Medicine and Research Institute of Veterinary Medicine (RIVM), Chungbuk National University, \\ Cheongju, South Korea and 'Laboratory of Mammalian Molecular Genetics, Department of Biochemistry, \\ College of Science, Yonsei University, Seoul, South Korea
}

\begin{abstract}
The balance between reactive oxygen species production and antioxidant defense enzymes in embryos is necessary for normal embryogenesis. To determine the dynamic expression profile of manganese superoxide dismutase (MnSOD) in embryos, which is an essential antioxidant enzyme in embryonic organogenesis, the expression level and distribution of MnSOD mRNA and protein were investigated in mouse embryos, as well as extraembryonic tissues on embryonic days (EDs) 7.5-18.5. MnSOD mRNA levels were remarkably high in extraembryonic tissues rather than in embryos during these periods. MnSOD protein levels were also higher in extraembryonic tissues than in embryos until ED 16.5, but the opposite trend was found after ED 17.5. MnSOD mRNA was observed in the chorion, allantois, amnion, ectoderm, ectoplacental cone and neural fold at ED 7.5 and in the neural fold, gut, ectoplacental cone, outer extraembryonic membranes and primitive heart at ED 8.5. After removing the extraembryonic tissues, the prominent expression of MnSOD mRNA in embryos was seen in the sensory organs, central nervous system and limbs on EDs 9.512.5 and in the ganglia, spinal cord, sensory organ epithelia, lung, blood cells and vessels, intestinal and skin epithelia, hepatocytes and thymus on EDs 13.5-18.5. Strong MnSOD immunoreactivity was observed in the choroid plexus, ganglia, myocardium, blood vessels, heapatocytes, pancreatic acinus, osteogenic tissues, brown adipose tissue, thymus and skin. These findings suggest that MnSOD is mainly produced from extraembryonic tissues and then may be utilized to protect the embryos against endogenous or exogenous oxidative stress during embryogenesis.
\end{abstract}

KEY WORDS: MnSOD, oxidative stress, organogenesis, mouse embryo, expression profile

Normally, metabolism of mammalian cell continuously generates reactive oxygen species (ROS) which influence cell signaling pathways including those involved in proliferation, differentiation, and apoptosis during embryo development. Balance between ROS production and antioxidant enzymes prevents lipid peroxidation, DNA and RNA breakages, protein degradation, and inactivation of many enzymes (Valko et al., 2007). In the defense system against oxidative stress, superoxide dismutase (SOD) is the first enzymatic step that converts superoxide ions $\left(\mathrm{O}_{2}^{-}\right)$to hydrogen peroxide $\left(\mathrm{H}_{2} \mathrm{O}_{2}\right)$. $\mathrm{O}_{2}{ }^{-}$is generated under physiological conditions as a by-product of mitochondrial respiration. At present, three distinct isoforms of SOD have been identified in mammals. There are two important types of intracellular SODs: the cytoplasmic copper/zinc SOD (SOD1) and mitochondrial manganese SOD (MnSOD: SOD2). MnSOD is located in the mitochondrial matrix and protects mitochondria from the $\mathrm{O}_{2}^{-}$that is detrimental to these organelles. Therefore, MnSOD is highly expressed in organs whose tissues contain a large number of mitochondria such as the heart, liver, and kidney (Beyer et al., 1991; Fridovich, 1995; Landis and Tower, 2005).

MnSOD knockout mice died of severe dilated cardiomyopathy, neurodegeneration, and severe metabolic acidosis during development within a few days after birth (Lebovitz et al., 1996; Huang et al., 2001). Knockout mice with targeted disruption of MnSOD are more susceptible to damage than their wild-type counterparts (Grzeschik et al., 2003; Ong et al., 2006). For example, animals lacking MnSOD develop a variety of abnormalities such as sideroblastic anemia, increased incidence of cancer, genomic instability, spongiform encephalopathy, optic neuropathy, movement disor-

Abbreviations used in this paper: ED, embryonic day; MnSOD, manganese superoxide dismutase.

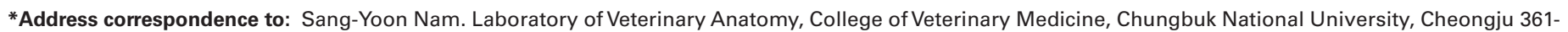
763, South Korea.Tel: +82-43-261-2596 - Fax: +82-43-271-3246 - e-mail: synam@cbu.ac.kr 


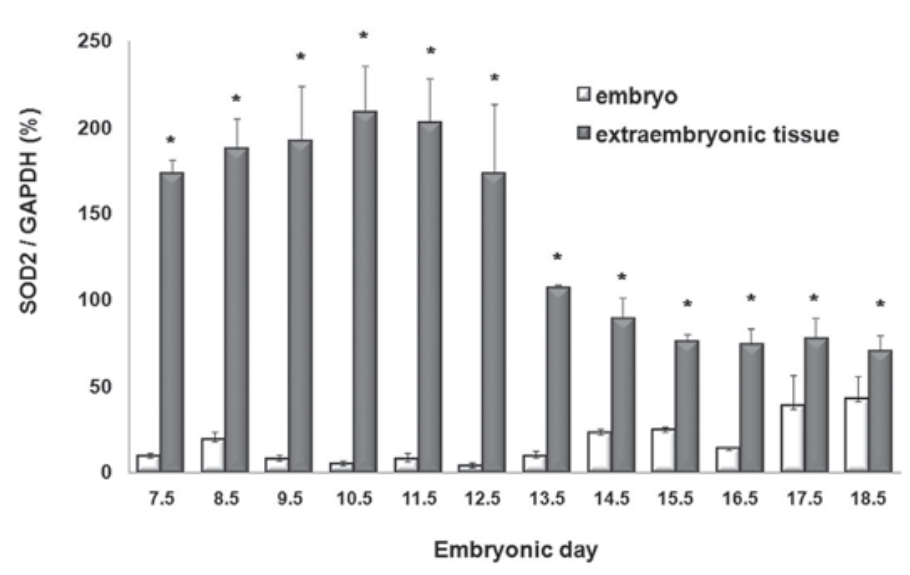

ders, neurodegeneration, and mitochondrial biochemical defects (Melov et al., 1998; Qi et al., 2003; Samper et al., 2003; Hinerfeld et al., 2004; Lynn et al., 2005; Martin et al., 2006). On the contrary, transgenic mice overexpressing MnSOD in pulmonary tissue are conspicuously resistant to oxygen toxicity (Ibrahim et al., 2000), and those overxpressing MnSOD in the heart are protective against adriamycin-induced cardiac toxicity (Cole et al., 2006) or myocardial ischemia-reperfusion injury (Chen et al., 1998). Additionally, overexpression of MnSOD in the lungs of mice prior to irradiation treatment prevents acute and chronic irradiation-induced damage (Carpenter et al., 2005).

Therefore, it has been postulated that MnSOD may be important for embryogenesis, and thus it is necessary to acquire further comprehensive and detailed knowledge about the roles and functions of MnSOD during embryogenesis. The principal objective of the present study was to quantify the relative expression levels and to identify the specific localization of MnSOD during mouse embryogenesis. The analysis of MnSOD expression in normal embryonic tissue may help estimate the specific physiological functions of MnSOD.

\section{Results}

Temporal levels of MnSOD mRNA and protein in developing embryos and extraembryonic tissues during organogenesis

The temporal expression pattern of MnSOD mRNA was assessed using quantitative real-time PCR analysis. As shown in Fig. 1, MnSOD mRNA was detected in all the embryos and extraembryonic tissues including placenta on EDs 7.5-18.5. MnSOD mRNAlevel was higher in the extraembryonic tissues than in embryos during the gestation period examined (10- to 47-fold on EDs 7.5-13.5 and then 2- to 5-fold until ED 18.5). MnSOD mRNA in extraembryonic tissues was expressed at a high level until ED 12.5 and then showed a decreasing pattern after ED13.5. On the other hand, the signal for MnSOD mRNA in embryos increased gradually during the whole gestational periods examined.

As analyzed by Western blotting, MnSOD protein was detected in embryos and extraembryonic tissues including placenta on EDs 8.5-18.5. MnSOD protein
Fig. 1. Relative MnSOD mRNA levels in developing embryos or extraembryonic tissues. Mouse embryos and extraembryonic tissues were prepared at different developmental stages (EDs 7.5-18.5). Total RNA was extracted and analyzed by real-time polymerase chain reaction. Relative MnSOD mRNA levels were analyzed using the specific Taqman probe primers. MnSOD mRNA levels were higher in the extraembryonic tissues than in embryos during the gestation periods. GAPDH mRNA was used as an internal standard. Each data represent mean $\pm S D$ from mouse embryos and extraembryonic tissues $(n=5) .{ }^{*}$, significantly different from the embryonic expression at $p<0.05$.

levels were higher in extraembryonic tissues than embryos until ED 16.5 (1.2- to 3.2-fold), but the reverse pattern was observed after ED 17.5 (0.6- to 0.8-fold). The signals gradually increased in the embryos during development (Fig. 2). In extraembryonic tissues, although the MnSOD protein level was highest on EDs 8.5-9.5, it was slightly reduced after ED 10.5 and was lowest at ED 18.5 (Fig. 2).

\section{Localization of MnSOD mRNA in whole mount embryos of EDs 7.5-12.5}

At ED 7.5, MnSOD mRNA was expressed in the chorion, amnion, ectoderm, neural fold, and ectoplacental cone (Fig. 3A). At ED 8.5, signal was detected in the neural fold, primitive heart, gut, ectoplacental cone, and outer extraembryonic membranes (Fig. 3B). After removing the extraembryonic tissues, MnSOD transcript was detected in brain including the telencephalon, mesencephalon, and myelencephalon, spinal cord, branchial bar I (mandibular arch), ventricle of heart, limb buds, and gut on EDs 9.5-10.5 (Fig. 3 C,D).
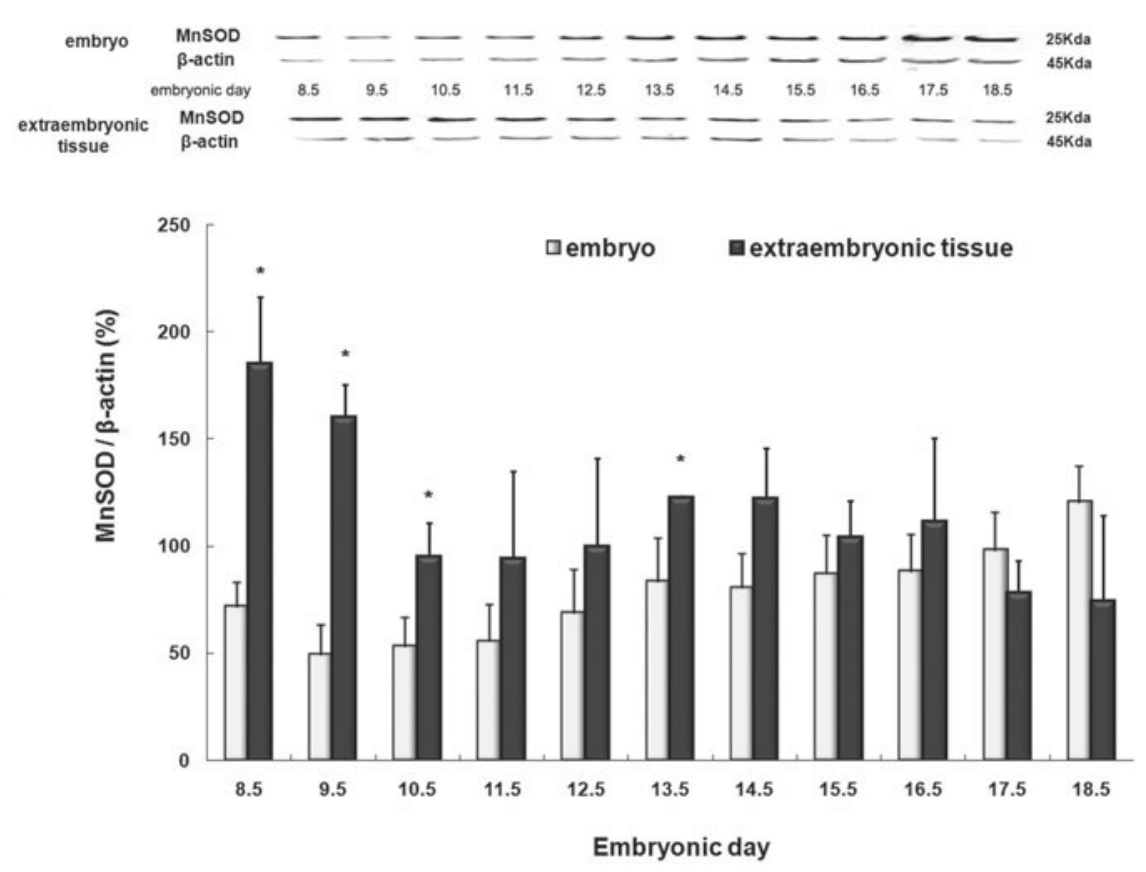

Fig. 2. Relative MnSOD protein levels in developing embryos or extraembryonic tissues. Mouse embryos and extraembryonic tissues were prepared at different developmental stages (EDs 8.5-18.5). Total protein was extracted and analyzed by Western blotting MnSOD protein levels were high in extraembryonic tissues than embryos until ED 16.5, but the reverse was observed after ED 17.5. Beta-actin was used as an internal standard. Each data represent mean $\pm S D$ from mouse embryos and extraembryonic tissues $(n=5)$. *, significantly different from the embryonic expression at $p<0.05$. 
TABLE 1

COMPARISON OF MnSOD MRNA EXPRESSION IN DEVELOPING EMBRYONIC ORGANS

\begin{tabular}{|c|c|c|c|c|c|c|c|c|}
\hline \multirow{2}{*}{ Organs } & & \multicolumn{6}{|c|}{ Embryonic day* } \\
\hline & & & \multirow{2}{*}{$\begin{array}{c}13.5 \\
+\end{array}$} & \multirow{2}{*}{$\frac{14.5}{++}$} & \multirow{2}{*}{$\frac{15.5}{++}$} & \multirow{2}{*}{$\begin{array}{c}16.5 \\
++\end{array}$} & \multirow{2}{*}{$\frac{17.5}{++}$} & \multirow{2}{*}{$\frac{18.5}{++}$} \\
\hline \multirow{6}{*}{$\begin{array}{l}\text { Nervous } \\
\text { tissues }\end{array}$} & \multicolumn{2}{|c|}{ | Cerebral cortex } & & & & & & \\
\hline & \multicolumn{2}{|c|}{ Choroid plexus } & ++ & ++ & ++ & ++ & ++ & + \\
\hline & \multicolumn{2}{|c|}{ Cerebellum } & + & ++ & ++ & ++ & ++ & + \\
\hline & \multicolumn{2}{|c|}{ Rathke's pouch (hypophysis) } & ++ & ++ & nc & + & + & + \\
\hline & \multicolumn{2}{|l|}{ Ganglia } & +++ & +++ & +++ & +++ & +++ & +++ \\
\hline & \multicolumn{2}{|l|}{ Spinal cord } & ++ & ++ & +++ & +++ & +++ & +++ \\
\hline \multirow{2}{*}{$\begin{array}{l}\text { Sensory } \\
\text { organs }\end{array}$} & \multicolumn{2}{|c|}{ Olfactory epithelium } & ++ & ++ & +++ & +++ & ++ & ++ \\
\hline & \multicolumn{2}{|c|}{ Inner ear epithelium } & $\mathrm{nc}$ & ++ & +++ & +++ & ++ & ++ \\
\hline \multirow{2}{*}{$\begin{array}{l}\text { Respiratory } \\
\text { Organs }\end{array}$} & \multirow{2}{*}{ Lung } & Parenchyma & ++ & ++ & ++ & ++ & ++ & ++ \\
\hline & & Bronchial epithelium & ++ & ++ & ++ & ++ & ++ & ++ \\
\hline \multirow{3}{*}{$\begin{array}{l}\text { Circulatory } \\
\text { organs }\end{array}$} & & + & + & ++ & + & + & \pm \\
\hline & \multicolumn{2}{|c|}{ Blood cells } & +++ & +++ & +++ & +++ & ++ & ++ \\
\hline & \multicolumn{2}{|c|}{ Blood vessels } & ++ & ++ & ++ & ++ & ++ & ++ \\
\hline \multirow{7}{*}{$\begin{array}{l}\text { Digestive } \\
\text { organs }\end{array}$} & \multirow{2}{*}{ Intestine } & Epithelium & ++ & ++ & ++ & ++ & ++ & ++ \\
\hline & & Muscular layer & + & + & + & ++ & ++ & + \\
\hline & \multirow{2}{*}{ Liver } & Hepatocyte & ++ & +++ & +++ & +++ & ++ & ++ \\
\hline & & Hematopoietic cells & +++ & +++ & +++ & + & + & \pm \\
\hline & Pancreas & Acinus & ++ & ++ & + & + & ++ & + \\
\hline & Pancreas & Islet & + & ++ & ++ & + & + & + \\
\hline & Submandik & land & + & + & ++ & ++ & ++ & ++ \\
\hline & Kidnev & Metanephric corpuscle & + & + & + & + & + & ++ \\
\hline & Rrunty & Metanephric tubule & + & ++ & ++ & ++ & ++ & ++ \\
\hline Urinary & Urinary & Epithelium & nc & nc & + & ++ & ++ & $\mathrm{nc}$ \\
\hline organs & bladder & Muscular layer & $\mathrm{nc}$ & $\mathrm{nc}$ & + & ++ & ++ & + \\
\hline & Adrenal & Medulla & ++ & ++ & ++ & $\mathrm{nc}$ & ++ & + \\
\hline & gland & Cortex & ++ & ++ & + & $\mathrm{nc}$ & + & \pm \\
\hline Thymus & & & + & ++ & ++ & ++ & ++ & ++ \\
\hline Bone & & & ++ & ++ & + & + & + & + \\
\hline Skin & & & \pm & + & + & +++ & +++ & +++ \\
\hline Skeletal mus & & & \pm & + & + & ++ & + & + \\
\hline Brown adipo & se tissue & & nc & $\mathrm{nc}$ & ++ & +++ & ++ & ++ \\
\hline
\end{tabular}

*Signal intensity: \pm , weak; +, moderate; ++, strong; +++, very strong; nc, not checked.

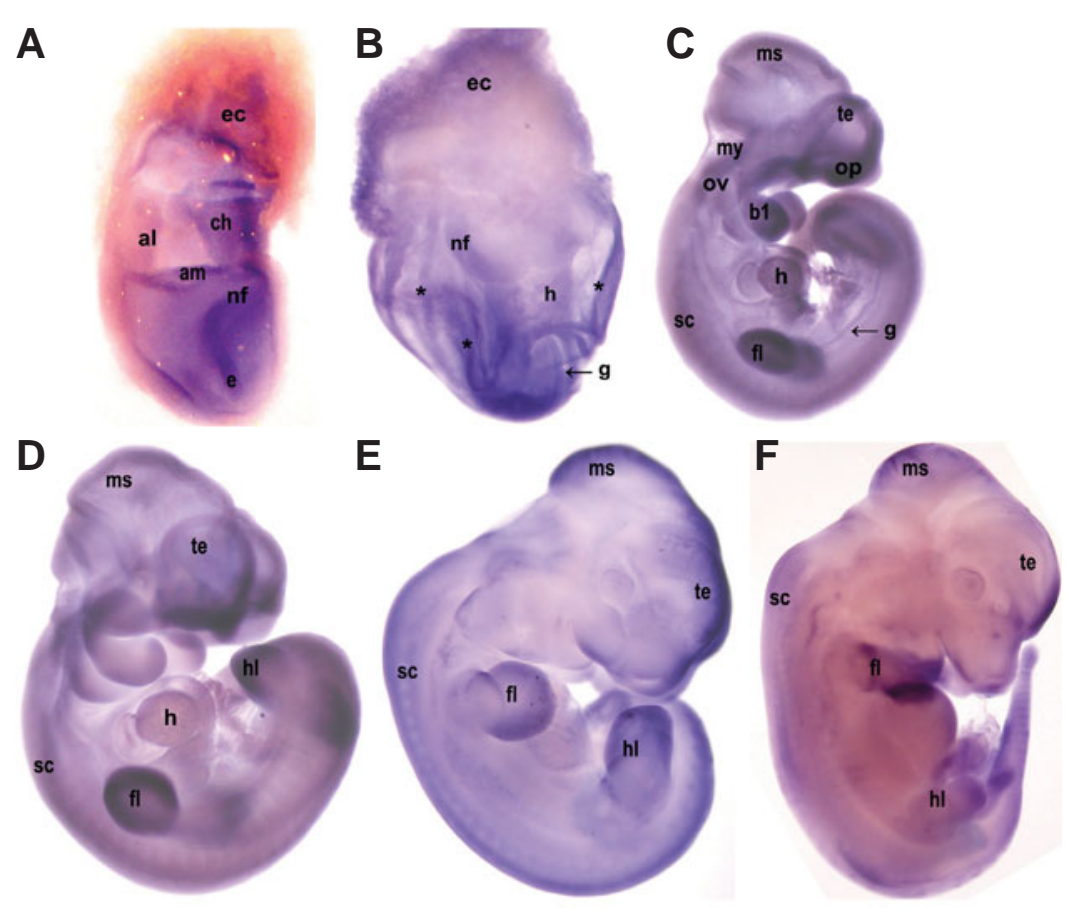

On EDs 11.5-12.5, MnSOD mRNA was expressed in the telencephalon, mesencephalon, spinal cord, and limb buds (Fig. 3 E,F).

\section{Localization of MnSOD mRNA in embryonic organs of EDs 13.5-18.5}

$M n S O D$ mRNA was detected in various embryonic tissues on EDs 13.5-18.5. The temporal location pattern is summarized in Table 1. MnSOD mRNA in the developing brain was detected at high levels in the external layers of the cerebral cortex on EDs 13.5 to 18.5 (Fig. 4A) and in marginal zone of the cerebellum on ED 18.5 (Fig. 4B). Very strong MnSOD signal was observed in the neurons of developing ganglion and spinal cord on EDs 13.5 to 18.5 (Fig. 4C,D). MnSOD mRNA was strongly expressed in epithelial cells of the nasal cavity and inner ear after ED 13.5 (Fig. 4 E,F). In the developing lung, high levels of MnSOD mRNA were observed in the bronchial epithelium and parenchyma after ED 13.5 (Fig. 4 G,H). MnSOD signal was detected at a high level after ED 13.5 in blood cells (Fig. 4I) and at a moderate level in the myocardium on ED 17.5 (Fig. 4J). In developing intestines, MnSOD mRNA was more strongly expressed in luminal epithelium than muscular layer on EDs 13.5-15.5, but it was highly expressed in both regions on EDs 16.5-17.5 (Fig. $4 \mathrm{~K}, \mathrm{~L}$ ). MnSOD mRNA expression was very strong in hepatocytes and hematopoietic cells of the liver on EDs 13.5-15.5 (Fig. 4M) and exclusively in hepatocytes after ED 16.5 (Fig. 4N). Strong MnSOD signal was observed in pancreatic acini on EDs 13.5-14.5 and 17.5 (Fig. 4O) or pancreatic islet on EDs 14.5-15.5 (Fig. 4P). A high level of MnSOD mRNA was detected in submandibular gland after ED 15.5 and in the thymus after ED 14.5 (Table 1). In developing kidney, strong MnSOD signal was observed in the metanephric tubules after ED 14.5 (Fig. 4 Q,R). MnSOD mRNA was abundant in the luminal epithelium and muscular layers of the urinary bladder on EDs 16.5-17.5 (Fig. 4S). In developing adrenal gland, MnSOD mRNA was highly expressed in the medulla on EDs 13.5-15.5 and 17.5 and in the cortex on EDs 13.5-14.5. MnSOD mRNA showed a moderate expression level in osteogenic tissue after ED 15.5 (Fig. 4T). In the developing skin, MnSOD mRNA expression was moderate on EDs 14.5-15.5 (Fig. 4U) and very high after ED 16.5 (Fig. 4V). In addition, MnSOD mRNA was remarkably detected in brown adipose tissue on EDs 15.5 -18.5 (Fig. 4W).

\section{Distribution of immunoreactive MnSOD in embryonic organs of EDs 13.5-18.5}

The temporal distribution and quantitative expres-

Fig. 3. Whole-mount in situ hybridization of MnSOD mRNA. (A) AtED 7.5, MnSOD mRNA was expressed in the ectoplacental cone (ec), chorion (ch), allantois (al), amnion (am), neural fold (nf), and ectoderm (e). (B) At ED 8.5, the signal for MnSOD mRNA was detected in the ec, nf, gut (arrow; $g$ ), primitive heart (h), and outer extraembryonic membranes (asterisks). (C) After removing the extraembryonic tissues, MnSOD mRNA was expressed in the telencephalon (te), mesencephalon (ms), myelencephalon (my), spinal cord (sc), branchial bar I (b1), h, forelimb bud (fl), otic vesicle (ov), olfactory pit (op), and g (arrow) at ED 9.5. (D) At ED 10.5, MnSOD mRNA was found in the te, $m s, s c, h$, and fland hindlimb (hl) buds. (E,F) On EDs 11.5-12.5, MnSOD mRNA was observed in the te, $\mathrm{ms}, \mathrm{sc}$, and $\mathrm{fl}$ and $\mathrm{hl}$ buds. 
sion of MnSOD protein during organogenesis was summarized in Table 2. In developing brain, MnSOD immunoreactivity was found at a moderate level in the cerebral cortex until EDs 17.5 and then increased at ED 18.5 (Fig. 5A). Moderate MnSOD immunoreactivity was observed in cerebellum on EDs 13.5-18.5. Strong MnSOD immunoreactivity was observed in the ependymal cells of the choroid plexus on EDs 13.5-18.5 (Fig. 5B), Rathke's pouch (hypophysis) after ED 15.5 (Fig. 5C), and neurons of the ganglia on EDs 13.5-18.5 (Fig. 5D) and spinal cords after ED 16.5 (Fig. $5 E)$. MnSOD was highly expressed in the epithelia of the inner ear and nasal cavity after ED 15.5. In developing lung tissues, MnSOD showed high expression in the bronchial epithelium after ED 16.5, but moderate expression in parenchyma after ED 15.5 (Fig. 5F). Strong MnSOD immunoreactivity was detected in myocardial cells and blood vessels on EDs 13.5-18.5, and in blood cells on EDs 13.5-16.5 (Fig. 5G and 5H). In developing intestines, strong MnSOD immunoreactivity was detected in the luminal epithelium after ED 14.5, but showed a moderate level in the muscular layer on EDs 13.5-17.5 (Fig. 5I). In developing liver, while MnSOD immunoreactivity in hepatocytes was very strong on EDs 13.518.5 , high signal levels in hematopoietic cells were observed on EDs 13.5-15.5 that then decreased to a moderate level after ED 16.5 (Fig. 5J). In developing pancreas, MnSOD immunoreactivity was detected at a high level in the acinus, but only moderately in islets on EDs 13.5-18.5 (Fig. 5K). In developing submandibular glands, high levels of MnSOD were detected on EDs 17.5-18.5. In developing kidneys, MnSOD showed a similar immunoreactivity level in metanephric corpuscles and tubules on EDs 13.5-14.5, but after ED 15.5, this was higher in metanephric tubules than metanephric corpuscles (Fig. 5L). In developing adrenal glands, MnSOD immunoreactivity was very strong in the medulla on EDs 14.5 and 16.5, and in the cortex on ED 18.5 (Fig. 5 M,N). Strong MnSOD immunoreactivity was observed in the developing thymus and bones after ED 13.5 (Fig. 5O). MnSOD was abundantly ob-

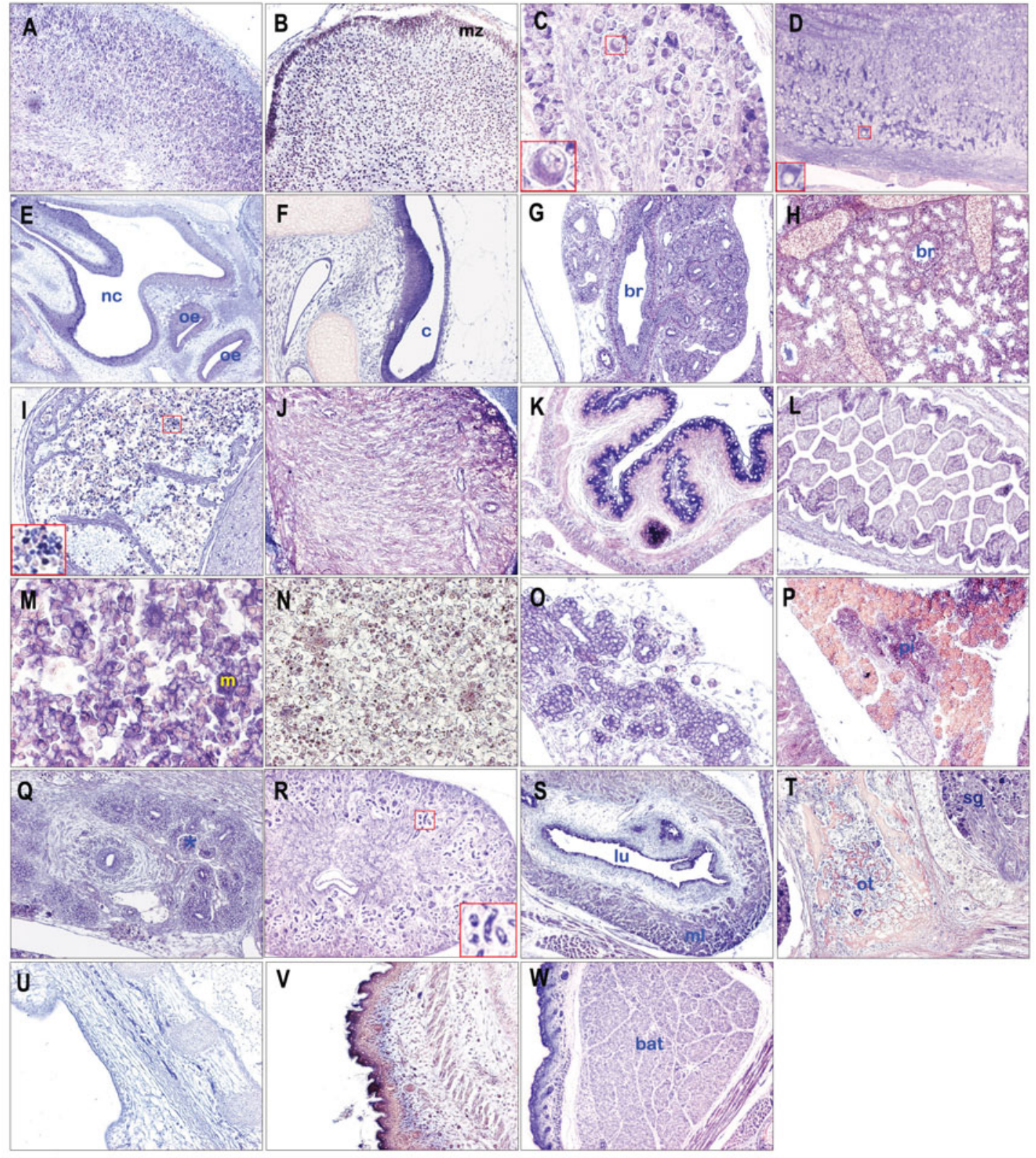

Fig. 4. Tissue-specific expression of MnSODmRNA in developing embryonic organs observed by hybridization with MnSODantisense riboprobes on the sagittal sections of mouse embryos. (A) $E D 17.5$ cerebral cortex. (B) ED 18.5 cerebellum; marginal zone (mz). (C) ED 17.5 ganglion; neuron (rectangle; x533). (D) ED 16.5 spinal cord; neuron (rectangle; x225). (E) ED 15.5 nasal cavity epithelium; nasal cavity (nc) and olfactory epithelium (oe). (F) ED 16.5 inner ear epithelium; cochlea (c). (G) ED 14.5 lung; bronchus (br). (H) ED 17.5 lung; bronchus (br). (I) ED 15.5 cardiac atrium; blood cells (rectangle; x285). (J) ED 17.5 ventricle of heart. (K) ED 17.5 stomach. (L) ED 17.5 intestine. (M) ED 14.5 liver; megakaryocyte (m). (N) ED 17.5 liver. (O) ED 14.5 pancreatic tubules. (P) ED 17.5 pancreatic islet (pi). (0) ED 14.5 kidney; metanephric tubule (asterisk). (R) ED 18.5 kidney; metanephric tubules (rectangle; $\times 113$ ). (S) ED 17.5 urinary bladder; lumen (lu) and muscle layer $(\mathrm{m} /)$. (T) $E D$ 17.5 osteogenic tissue (ot) and spinal ganglion (sg). (U) ED 14.5 skin. (V) ED 18.5 skin. (W) ED 17.5 brown adipose tissue (bat). Magnifications: 40x for panels (E, R, S, and W); 100x for panels (A, B, D, F-L, P, Q, and T-V); 200x for panels (C, N, and O); 400x for panel (M). 


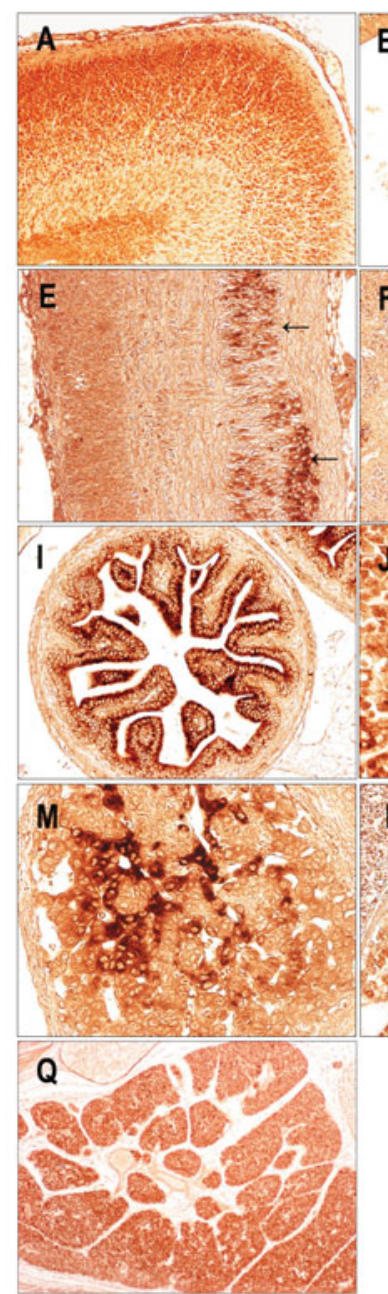

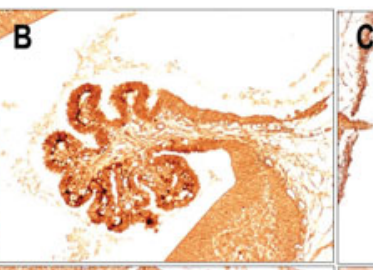
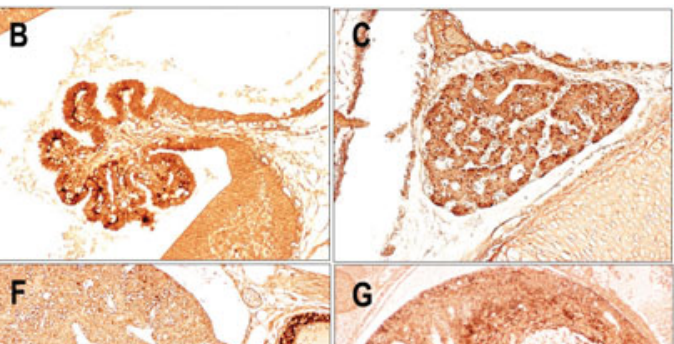

F

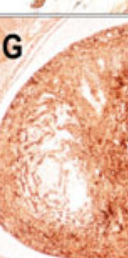

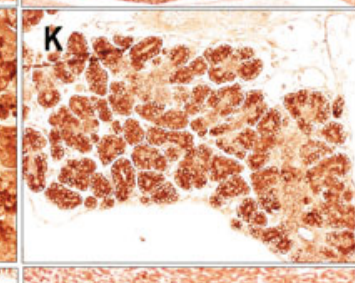

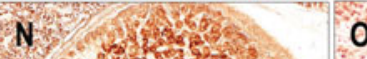

0
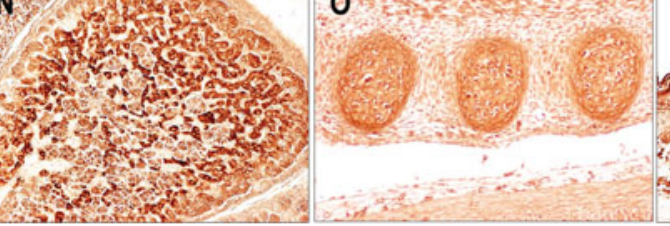

Fig. 5. Tissue-specific expression of MnSOD protein in developing embryonic organs. (A) ED 18.5 cerebrum. (B) ED 14.5 ependymal cells of choroid plexus. (C) ED 18.5 hypophysis. (D) ED 18.5 trigeminal ganglion. (E) ED 14.5 spinal cord; neurons (arrows). (F) ED 16.5 lung; bronchus (br) and blood vessels (bv). (G) ED 15.5 ventricle of heart. (H) ED 14.5 blood cells. (I) ED 16.5 intestine. (J) ED 15.5 hepatocytes and hematopoietic cells of liver. (K) ED 16.5 pancreas. (L) ED 18.5 kidney. (M) ED 14.5 adrenal gland. (N) ED 18.5 adrenal gland. (O) ED 13.5 osteogenic tissue. (P) ED 18.5 skin. (Q) ED 17.5 brown fat. Magnifications: 40x for panels (G, O, P, and Q); 100x for panels (A- F, I, K, L, and $N$;) 200x for panels ( $H$ and M); $400 x$ for panel (J).

served in skeletal muscle after ED 16.5. MnSOD signal was very strong in the skin after ED 16.5 and brown adipose tissues after ED 15.5 (Fig. 5 P,Q).

\section{Discussion}

During normal embryo development, the embryos generate ROS by both aerobic and anaerobic metabolic pathways, and require an antioxidant defense system (Ornoy, 2007). Need for oxygen varies with embryo development. Therefore, embryonic antioxidant defense is changed according to the time and site of organogenesis (el-Hage and Singh, 1990). ROS are produced during normal pregnancy through the metabolic activity of embryo and placental mitochondria (Dennery, 2007; Myatt, 2006). Several antioxidative defense mechanisms are present in both embryos and their surroundings. The transcript of the cytosolic glutathione peroxidase (cGPx) which removes $\mathrm{H}_{2} \mathrm{O}_{2}$ by coupling its reduction to $\mathrm{H}_{2} \mathrm{O}$ with oxidation of reduced glutathione, is detected in all the embryos retrieved from EDs 7.5 to 18.5 (Baek et al., 2005). SOD1 mRNA is increased at late stages of embryonic development, but maintains a constant level of expression in extraembryonic tissues during organogenesis (Yon et al., 2008a). In embryo, SOD1 protein
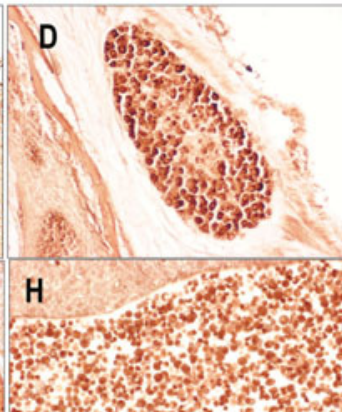

H

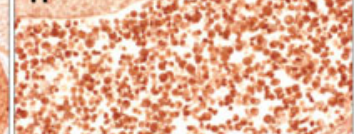

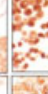
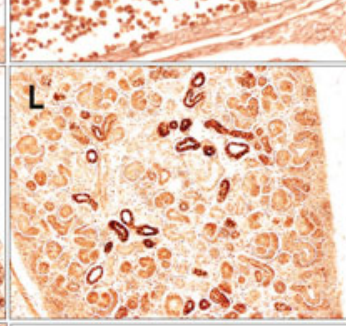

$\mathbf{P}$

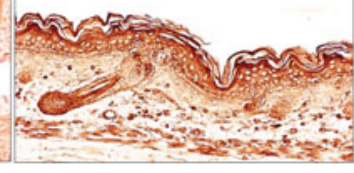

is observed at the lowest level on ED 9.5-11.5, and the highest level on ED 17.5-18.5, while levels remained constant in the extraembryonic tissues during all developmental stages (Yon et al., 2008b). The transcript of the selenoprotein $\mathrm{P}$ (SePP) which functions principally as a selenium transporter and antioxidant is high in extraembryonic tissues, as compared to embryos, on EDs 7.5-13.5. However, the level is higher in embryos than in extraembryonic tissues on EDs 14.5-15.5, but is similar in both tissues during the subsequent periods prior to birth (Lee et al., 2008). In the present study, MnSOD mRNAwas highly expressed in extraembryonic tissues rather than embryos. MnSOD mRNA expression constantly increased in embryos during development, but in extraembryonic tissues, MnSOD mRNA was expressed a high level until ED 12.5 before decreasing after ED 13.5. MnSOD protein levels were also higher in extraembryonic tissues than embryos until ED 16.5; the reverse was observed after ED 17.5. These findings indicate that the expression of various antioxidant enzymes including

MnSOD may be changed in embryos and extraembryonic tissues according to ontogenic stages and may play an important part in embryogenesis.

Decidual tissues originate from the maternal endometrial fibroblast and differentiate into structures surrounding the implanting embryos. These generally form a barrier and provide nutrition for embryo (Bell et al., 1983). During early postimplantational periods, a process of gastrulation and early organogenesis causes increment in ROS formation. Multiple compensatory protection mechanisms exist in the developing embryo and its environment (Dennery, 2007; Jansson and Powell, 2007; Ornoy, 2007). Uteroplacental circulation is established after implantation. The placenta receives nutrients, oxygen, antibodies, and hormones from maternal blood and passes waste products (Hanson, 2007). The oxygen requirements for rodent embryos vary during embryo development (Chen et al., 1999). As the fetus moves from a hypoxic to a relatively hyperoxic environment, accompanying changes in antioxidant enzymes constitute a compensatory mechanism aimed at protecting the newborn from oxidative stress (Khan and Black, 2003). In the present study, MnSOD mRNA was found in chorion, allantois, and amnion as well as extraembryonic tissues including placenta. Furthermore, MnSODlevels were high in extraembryonic 
tissues compared to the embryos until ED 16.5, but the reverse was observed after ED 17.5. MnSOD showed a gradual increase in the embryos during development. It is presumed that MnSOD might serve as an important player at the maternal-fetal interface which has a central role in fetal growth by directly regulating nutrients, respiratory gases, and signaling molecules.

In the early developmental stage, the central nervous system (CNS) begins as a simple neural plate region of the ectoderm and then folds to form the neural fold and groove. The tube is formed by the dorsal fusion of the neural folds and differentiates into the spinal cord and the brain (Padmanabhan, 2006). In the present study, MnSODmRNAwas abundantly expressed in the neural ectoderm and neural fold on EDs 7.5-8.5. Furthermore, MnSOD mRNA (EDs 9.5-18.5) and its protein (EDs 13.5-18.5) were abundantly expressed in the CNS including the prosencephalon, telencephalon, mesencephalon, metencephalon, and spinal cord, and various ganglia. These expression patterns were quite similar to those of SOD1, cGPx, and SePP (Baek et al., 2005; Lee et al., 2008; Yon et al., $2008 \mathrm{a}, \mathrm{b})$. Previous studies found that the developing limb and brain in fetus are the most sensitive to $\mathrm{O}_{2}$ - formation (Fantel et al., 1995). Neurons in the brain consume high amounts of oxygen, and are thereby constantly submitted to oxidative stress. SOD1 is mainly found in neuronal cells (Peluffo et al., 2005). Taken together, the data presented in this study suggest the possibility that antioxidant enzymes including MnSOD may play an important part

\section{TABLE 2}

\section{COMPARISON OF MnSOD IMMUNOREACTIVITY IN DEVELOPING ORGANS}

\begin{tabular}{|c|c|c|c|c|c|c|c|c|}
\hline \multirow{2}{*}{ Organs } & & \multicolumn{6}{|c|}{ Embryonic day* } \\
\hline & & & \multirow{2}{*}{$\begin{array}{c}13.5 \\
+\end{array}$} & \multirow{2}{*}{$\begin{array}{c}14.5 \\
+\end{array}$} & \multirow{2}{*}{$\begin{array}{c}15.5 \\
+\end{array}$} & \multirow{2}{*}{$\begin{array}{c}16.5 \\
+\end{array}$} & \multirow{2}{*}{$\begin{array}{c}17.5 \\
+\end{array}$} & \multirow{2}{*}{$\begin{array}{c}18.5 \\
++\end{array}$} \\
\hline \multirow{6}{*}{$\begin{array}{l}\text { Nervous } \\
\text { tissues }\end{array}$} & \multicolumn{2}{|c|}{ Cerebral cortex } & & & & & & \\
\hline & \multicolumn{2}{|c|}{ Choroid plexus } & ++ & ++ & ++ & ++ & +++ & ++ \\
\hline & \multicolumn{2}{|c|}{ Cerebellum } & + & + & + & + & + & + \\
\hline & \multicolumn{2}{|c|}{ Rathke's pouch (hypophysis) } & + & + & ++ & ++ & ++ & ++ \\
\hline & \multicolumn{2}{|l|}{ Ganglia } & ++ & ++ & +++ & +++ & +++ & +++ \\
\hline & \multicolumn{2}{|c|}{ Spinal cord } & + & + & + & ++ & ++ & ++ \\
\hline \multirow{2}{*}{$\begin{array}{l}\text { Sensory } \\
\text { organs }\end{array}$} & \multirow{2}{*}{\multicolumn{2}{|c|}{$\begin{array}{l}\text { Olfactory epithelium } \\
\text { Inner ear epithelium }\end{array}$}} & + & + & ++ & ++ & ++ & ++ \\
\hline & & Inner ear epithelium & $\mathrm{nc}$ & + & ++ & $\mathrm{nc}$ & +++ & ++ \\
\hline \multirow{2}{*}{$\begin{array}{l}\text { Respiratory } \\
\text { organs }\end{array}$} & \multirow{2}{*}{ Lung } & Parenchyma & \pm & \pm & + & + & + & + \\
\hline & & Bronchial epithelium & + & + & + & ++ & ++ & ++ \\
\hline \multirow{3}{*}{$\begin{array}{l}\text { Circulatory } \\
\text { organs }\end{array}$} & \multicolumn{2}{|c|}{ Myocardium } & ++ & ++ & +++ & +++ & ++ & +++ \\
\hline & Blood cell & & +++ & +++ & +++ & ++ & + & + \\
\hline & \multicolumn{2}{|c|}{ Blood vessels } & ++ & ++ & ++ & ++ & +++ & +++ \\
\hline \multirow{7}{*}{$\begin{array}{l}\text { Digestive } \\
\text { organs }\end{array}$} & \multirow{2}{*}{ Intestine } & Epithelium & + & ++ & +++ & +++ & ++ & ++ \\
\hline & & Muscular layer & + & + & + & + & + & \pm \\
\hline & \multirow{2}{*}{ Liver } & Hepatocyte & +++ & +++ & +++ & +++ & +++ & +++ \\
\hline & & Hematopoietic cells & ++ & ++ & ++ & + & + & + \\
\hline & \multirow{2}{*}{ Pancreas } & Acinus & ++ & ++ & +++ & +++ & ++ & ++ \\
\hline & & Islet & + & + & + & + & + & + \\
\hline & \multicolumn{2}{|c|}{ Submandibular gland } & + & + & + & + & ++ & ++ \\
\hline & Kidn & Metanephric corpuscle & + & + & + & + & $\mathrm{nc}$ & + \\
\hline Urinary & Kraney & Metanephric tubule & + & + & ++ & ++ & nc & ++ \\
\hline organs & Adrenal & Medulla & $\mathrm{nc}$ & +++ & $\mathrm{nc}$ & +++ & $\mathrm{nc}$ & + \\
\hline & gland & Cortex & $\mathrm{nc}$ & + & $\mathrm{nc}$ & ++ & $\mathrm{nc}$ & +++ \\
\hline Thymus & & & ++ & ++ & $\mathrm{nc}$ & ++ & ++ & ++ \\
\hline Bone & & & ++ & ++ & ++ & ++ & ++ & ++ \\
\hline Skin & & & + & + & + & +++ & +++ & +++ \\
\hline Skeletal mus & & & \pm & + & + & ++ & ++ & ++ \\
\hline Brown adipo & se tissue & & $\mathrm{nc}$ & $\mathrm{nc}$ & +++ & +++ & +++ & +++ \\
\hline
\end{tabular}

*Signal intensity: \pm , weak; +, moderate; ++, strong; +++, very strong; nc, not checked. in development of the nervous system as free radical scavengers.

The fetal lungs are exposed to relatively hypoxic environments which arise suddenly at birth, which may induce oxidative injury in neonates (Araujo et al., 1998). The epithelia are specifically differentiated to enable protection, absorption, secretion, excretion, and formation of a barrier for selective permeation (GonzalezMariscal et al., 2005). In current study, MnSOD was ubiquitously expressed in post-implatational mouse embryonic tissues. In particular, MnSOD appeared at high levels in the developmental epithelial systems such as metanephric tubules, bronchus, skin, whisker follicles, ependymal epithelium of choroid plexus, luminal epithelia in inner ear and nasal cavities, and intestinal mucosal epithelium. These results are in close agreement with those from studies of rat tissues (Munim et al., 1992) as well as antioxidant enzymes such as SOD1, cGPx, and SePP (Baek et al., 2005; Lee et al., 2008; Yon et al., 2008 a,b). Therefore, we suggest that MnSOD (SOD2) may function as the outmost antioxidant enzyme to protect embryos against detrimental ROS generated from fetal and maternal interaction during embryogenesis.

The majority of intracellular $\mathrm{O}_{2} \cdot-$ are generated from complexes I and III of the electron transport chain as a byproduct of oxidative phosphorylation in mitochondria (Rossignol et al., 2003). MnSOD is highly expressed in adult organs that contain a large number of mitochondria such as heart, brain, liver, and kidney, and reflect energy consumption rates (Guérin et al., 2001). MnSODknockout mice exhibit prenatal and neonatal lethality which is associated with defects in the heart, skeletal muscle, liver, and brain (Lebovitz et al., 1996; Li et al., 1995; Xia et al., 2006). In our study, MnSOD was strongly detected in developing brain, heart, liver, pancreas, kidney, skeletal muscle, and adrenal gland. Therefore, MnSOD may act as a critical antioxidant enzyme in organs with cells that have an abundance of mitochondria.

ROS are vital to normal developmental processes such as proliferation and differentiation (Dennery, 2007). In our study, strong MnSOD expression was observed in sites of active differentiation and proliferation such as chondrocytes of osteogenic tissues, hematopoietic cells of the liver, and circulatory blood cells. After birth, erythrocytes use SOD1 to scavenge $\mathrm{O}_{2}^{-}$but carry only the SOD1 protein, not mRNA, as they lack mitochondria. Neutrophils produce enormous quantities of $\mathrm{O}_{2}^{-}$through the activity of cellular oxidant-generating systems (Sheppard et al., 2005). High levels of SOD1 activity are present in cartilage and connective tissues (Frederiks and Bosch, 1997), and a low molecular weight of SOD mimetic attenuates chronic inflammation, tissue damage, and bone damage associated with collagen-induced arthritis (Cuzzocrea et al., 2005). Thus, MnSOD (SOD2), one of the SOD family including SOD1 may act as an important antioxidant in osteogenesis and hematopoiesis during embryonic development.

In this study, MnSOD was very strongly expressed in brown adipose tissue after ED 15.5. Brown adipose tissue serves as a thermogenic organ in placental mammals to maintain body temperature in cold environments (Cannon and Nedergaard, 2004) and contains many mitochondria, fat vacuoles, and a blood supply (Dawkins and Hull, 1964). Cold exposure increases MnSOD activity in interscapular brown adipose tissue in order to protect the tissue from ROS generated as a result of intense metabolic activity (Petrović et al., 2006). Therefore, MnSOD may play an important role in embryonic protection against ROS produced in the mitochondrial metabolism of brown adipose tissues during the 
gestational periods.

In summary, MnSOD levels varied widely in different cell types, and even within a particular cell type, during the course of embryonic development. Although the expression patterns between mRNAand protein of MnSOD were slightly different in the mouse embryonic organs, suggesting that the production site and functional site for MnSOD during embryogenesis may be different somewhat, most of MnSOD was expressed in embryos and extraembryonic tissues during post-implantational organogenesis in a specific pattern which is necessary for protecting the embryos against endogenous or exogenous oxidative stresses during embryogenesis. The overall results obtained in this study provide information which is used as a basis to study the functions of MnSOD relative to various diseases.

\section{Materials and Methods}

\section{Experimental animals}

Male and female ICR mice (8 10 weeks old) were purchased from a commercial breeder, Biogenomics Co. (Seoul, South Korea). One male and three female mice were mated overnight in our facilities, which were maintained at 21 $\pm 2^{\circ} \mathrm{C}$ and $55 \pm 10 \%$ relative humidity on a $12 \mathrm{~h} \mathrm{light/dark} \mathrm{cycle.} \mathrm{Pregnancy} \mathrm{was}$ confirmed the following morning by the presence of a vaginal plug, which was designated as embryonic day (ED) 0.5 . The pregnant mice were sacrificed by cervical dislocation and the embryos and extraembryonic tissues including the ectoplacental cone (placenta), chorion, amnion, allantois, yolksac, and Reichert's membrane were recovered at EDs 7.5 to 18.5. All experiments were performed in accordance with the "Guide for Care and Use of Animals" (Chungbuk National University Animal Care Committee according to NIH \#86-23).

\section{Total RNA isolation and quantitative RT-PCR analysis}

Total RNA was extracted from the mouse embryos and extraembryonic tissues using a Trizol reagent kit (Invitrogen, Calsbard, California, USA). Total RNA $(3 \mu \mathrm{g})$ was used for reverse transcription (RT) to generate cDNA using a cDNA synthesis kit (Invitrogen, Calsbard, CA, USA). The cDNA then served as a template for PCR reactions. Quantitative RT-PCR reactions were conducted using the TaqMan Universal PCR Master Mix Kit (Applied Biosystems, Foster, CA, USA) as previously described (Yon et al., 2008a). MnSOD cDNA amplification was conducted using a Model 7500 Real-Time PCR System by Assay on Demand \#Mm00690588 (Applied Biosystems). GAPDH mRNA was the internal standard (Assay on Demand \#4352932E, Applied Biosystems) for normalizing target transcript expression. The relative ratios of MnSOD mRNA to GAPDH mRNA, which were used to precisely quantify the levels of $M n S O D$ expression in embryos and extraembryonic tissues, were calculated with the standard curves. Duplicate sets of data from five independent runs were analyzed (mean $\pm S D$ ).

\section{In situ hybridization in whole embryos and embryonic tissues}

To prepare RNA probes for in situ hybridization, a pGEM-T easy plasmid (Promega, Madison, WI, USA) containing the mouse MnSOD cDNA clones (accession number: NM_013671, fragment; 287 bp) was linearized with Spel or Ncol restriction enzymes. Digoxigenin- (DIG; Roche, Penzberg, Germany) labeled sense or antisense riboprobes for $M n S O D$ were generated via in vitro transcription in the presence of T7 or Sp6 RNA polymerase (Takara, Shiga, Japan) at $37^{\circ} \mathrm{C}$ for $60 \mathrm{~min}$. For whole-mount in situ hybridization of embryos, EDs 7.5-12.5 mouse embryos were fixed in $4 \%$ paraformaldehyde in phosphatebuffered saline (PBS) overnight and dehydrated in methanol. The general in situ hybridization procedure for tissue sections (EDs 13.5-18.5) was carried out as previously described (Baek et al., 2005). Hybridization signals were detected using an alkaline phosphatase-conjugated antibody against DIG (Roche) and 5-bromo-4-chloro-3-indolyl phosphate and nitro-blue tetrazolium solution (Roche) substrate.

\section{Protein extraction and Western blotting}

Total protein was extracted from EDs 8.5-18.5 mouse embryos and extraembryonic tissues. Protein extraction and Western blotting were conducted as pre- viously described (Yon et al., 2008b). The anti-MnSOD polyclonal antibody was purchased from Stressgen (Ann arbor, MI, USA) and the anti- $\beta$-actin antibody was purchased from Cell Signaling (Denver, MA, USA). The secondary horseradish peroxidase-linked anti-rabbit IgG antibody was purchased from Cell Signaling. Membranes were incubated with the horseradish peroxidase-conjugated secondary antibody (1:1000; Cell Signaling) for $1 \mathrm{~h}$ at room temperature, visualized using a Western Lighting Chemiluminescence reagent (Millipore, Billerica, MA, USA) according to the manufacturer's protocol, and photographed (Gel Doc EQ, Bio-Rad, Hercules, CA, USA). Immunoreactive bands were quantified and normalized using PDQuest Image software (Bio-Rad). Experiments were performed in each five embryos and data are presented as mean \pm SD.

\section{Immunohistochemistry}

For immunohistochemical analysis, mouse embryos obtained on EDs 13.518.5 were fixed in Bouin solution. The $4 \mu \mathrm{m}$ embryo sagittal sections were placed on silane-coated slides, deparaffinized, immersed in PBS containing $0.3 \%$ (vol/ vol) hydrogen peroxide, and then processed in a microwave oven (in $10 \mathrm{mM}$ sodium citrate buffer, $\mathrm{pH} 6.5$, for 15 minutes at $700 \mathrm{~W}$ ). After blocking with $1.5 \%$ ( $\mathrm{vol} / \mathrm{vol}$ ) normal serum in PBS containing $0.05 \%$ (vol/vol) Tween-20 for $20 \mathrm{~min}$, the sections were incubated with a rabbit anti-MnSOD polyclonal antibody (dilution, 1:100; Stressgen) for $1 \mathrm{~h}$ at room temperature. Next, the sections were incubated with a biotinylated secondary antibody [dilution, 1:2000; Vectastain ABC-AP KIT (Rabbit Ig G); Vector Laboratories, Burlingame, CA, USA] for 30 min at room temperature and then with the peroxidase-conjugated biotin-avidin complex (dilution, 1:1000) for $40 \mathrm{~min}$ at room temperature. Finally, the bound peroxidase was revealed by immersing the sections in diaminobenzidine (Vector Laboratories). Sections were rehydrated for $15 \mathrm{~min}$ in deionized water to remove any precipitated Tris, and then dehydrated in a series of ethanol and xylene. Negative control experiments for the antibodies were performed as above with the omission of the primary antibody.

\section{Statistical analysis}

Expression differences of MnSOD mRNA and protein between embryos and extraembryonic tissues at each embryonic stage were assessed via oneway ANOVA followed by Student t-test. All analyses were conducted using a Graphpad Prism software, version 5 (GraphPad Software Inc., La Jolla, CA, USA). Statistical significance was evaluated at $P<0.05$. All data were expressed as mean $\pm \mathrm{SD}$.

\section{Acknowledgements}

This work was supported by the Priority Research Centers Program through the National Research Foundation of Korea (NRF) funded by the Ministry of Education, Science and Technology (2010-0029709).

\section{References}

ARAUJO, V., RUIZ, E., LLOVERA, M., TOKASHIKI, N., ABELLAN, C. and DOMINGUEZ, C. (1998). Impact of oxygen therapy on antioxidant status in newborns. Relationship with infection risk. Biofactors 8: 143-147.

BAEK, I.J., YON, J.M., LEE, B.J., YUN, Y.W., YU, W.J., HONG, J.T., AHN, B., KIM, Y.B., KIM, D.J., KANG, J.K. and NAM, S.Y. (2005). Expression pattern of cytosolic glutathione peroxidase (cGPx) mRNA during mouse embryogenesis. Anat Embryol (Berl) 209: 315-321.

BELL, E., SHER, S., HULL, B., MERRILL, C., ROSEN, S., CHAMSON, A., ASSELINEAU, D., DUBERTRET, L., COULOMB, B., LAPIERE, C., NUSGENS, B. and NEVEUX, Y. (1983). The reconstitution of living skin. J. Invest Dermatol 81:2s-10s.

BEYER, W., IMLAY, J. and FRIDOVICH, I. (1991). Superoxide dismutases. Prog Nucleic Acid Res Mol Biol 40: 221-253.

CANNON, B. and NEDERGAARD, J. (2004). Brown adipose tissue: function and physiological significance. Physiol Rev 84: 277-359.

CARPENTER, M., EPPERLY, M.W., AGARWAL, A., NIE, S., HRICISAK, L., NIU, Y. and GREENBERGER, J.S. (2005). Inhalation delivery of manganese superoxide dismutase-plasmid/liposomes protects the murine lung from irradiation damage. Gene Ther 12: 685-693.

CHEN, E.Y., FUJINAGA, M. and GIACCIA, A.J. (1999). Hypoxic microenvironment 
within an embryo induces apoptosis and is essential for proper morphological development. Teratology 60(4): 215-225.

CHEN, Z., SIU, B., HO, Y.S., VINCENT, R., CHUA, C.C., HAMDY, R.C. and CHUA, B.H. (1998). Overexpression of MnSOD protects against myocardial ischemia/ reperfusion injury in transgenic mice. J Mol Cell Cardiol 30: 2281-2289.

COLE, M.P., CHAISWING, L., OBERLEY, T.D., EDELMANN, S.E., PIASCIK, M.T., LIN, S.M., KININGHAM, K.K. and ST CLAIR, D.K. (2006). The protective roles of nitric oxide and superoxide dismutase in adriamycin-induced cardiotoxicity. Cardiovasc Res 69: 186-197.

CUZZOCREA, S., MAZZON, E., PAOLA, R.D., GENOVESE, T., MUIA, C., CAPUTI, A.P. and SALVEMINI, D. (2005). Effects of combination M40403 and dexamethasone therapy on joint disease in a rat model of collagen-induced arthritis. Arthritis Rheum 52: 1929-1940.

DAWKINS, M.J. and HULL, D. (1964). Brown adipose tissue and non-shivering thermogenesis in newborn animals. Maandschr Kindergeneeskd 32: 641-652.

DENNERY, P.A. (2007). Effects of oxidative stress on embryonic development. Birth Defects Res C Embryo Today 81: 155-162.

EL-HAGE, S. and SINGH, S., M. (1990). Temporal expression of genes encoding free radical-metabolizing enzymes is associated with higher mRNA levels during in utero development in mice. Dev Genet. 11: 149-159.

FANTEL, A.G., PERSON, R.E., TUMBIC, R.W., NGUYEN, T.D. and MACKLER, B. (1995). Studies of mitochondria in oxidative embryotoxicity. Teratology52: 190-195.

FREDERIKS, W.M. and BOSCH, K.S. (1997). Localization of superoxide dismutase activity in rat tissues. Free Radic Biol Med 22: 241-248.

FRIDOVICH, I. (1995). Superoxide radical and superoxide dismutases. Annu Rev Biochem 64: 97-112.

GONZALEZ-MARISCAL, L., NAVA, P. and HERNANDEZ, S. (2005). Critical role of tight junctions in drug delivery across epithelial and endothelial cell layers. $J$ Membr Biol 207: 55-68.

GRZESCHIK, S.M., MAIER, C.M. and CHAN, P.H. (2003). Effects of cold injuryinduced trauma in manganese superoxide dismutase-deficient mice. $J$ Neurotrauma 20: 571-581.

GUERIN, P., EL MOUATASSIM, S. and M N ZO, Y. (2001). Oxidative stress and protection against reactive oxygen species in the pre-implantation embryo and its surroundings. Hum Reprod Update. 7(2): 175-189.

HANSON, L.A. (2007). Session 1: Feeding and infant development breast-feeding and immune function. Proc Nutr Soc 66: 384-396.

HINERFELD, D., TRAINI, M.D., WEINBERGER, R.P., COCHRAN, B., DOCTROW, S.R., HARRY, J. and MELOV, S. (2004). Endogenous mitochondrial oxidative stress: neurodegeneration, proteomic analysis, specific respiratory chain defects, and efficacious antioxidant therapy in superoxide dismutase 2 null mice. $J$ Neurochem 88: 657-667.

HUANG, T.T., CARLSON, E.J., KOZY, H.M., MANTHA, S., GOODMAN, S.I., URSELL, P.C. and EPSTEIN, C.J. (2001). Genetic modification of prenatal lethality and dilated cardiomyopathy in Mn superoxide dismutase mutant mice. Free Radic Biol Med 31: 1101-1110

IBRAHIM, W., LEE, U.S., YEN, H.C., ST CLAIR, D.K. and CHOW, C.K. (2000). Antioxidant and oxidative status in tissues of manganese superoxide dismutase transgenic mice. Free Radic Biol Med 28: 397-402.

JANSSON, T. and POWELL, T.L. (2007). Role of the placenta in fetal programming: underlying mechanisms and potential interventional approaches. Clin Sci (Lond) 113: 1-13.

KHAN, J.Y. and BLACK, S.M. (2003). Developmental changes in murine brain antioxidant enzymes. Pediatr Res 54: 77-82.

LANDIS, G.N. and TOWER, J. (2005). Superoxide dismutase evolution and life span regulation. Mech Ageing Dev 126: 365-379.

LEBOVITZ, R., ZHANG, H., VOGEL, H., CARTWRIGHT, J.J., DIONNE, L., LU, N., HUANG, S. and MATZUK, M. (1996). Neurodegeneration, myocardial injury, and perinatal death in mitochondrial superoxide dismutase-deficient mice. Proc Natl Acad Sci USA. 93: 9782-9787.
LEE, S.R., YON, J.M., BAEK, I.J., KIM, M.R., PARK, C.G., LEE, B.J., YUN, Y.W and NAM, S.Y. (2008). Spatiotemporal expression of the selenoprotein P genein postimplantational mouse embryos. Int J Dev Biol 52: 1005-1011.

LI, Y., HUANG, T.T., CRLSON, E.J., MELOV, S., URSELL, P.C., OLSON, J.L., NOBLE, L.J., YOSHIMURA, M.P., BERGER, C., CHAN, P.H., WALLACE, D.C. and EPSTEIN, C.J. (1995). Dilated cardiomyopathy and neonatal lethality in mutant mice lacking manganese superoxide dismutase. Nat Genet 11: 376-381.

LYNN, S., HUANG, E.J., ELCHURI, S., NAEEMUDDIN, M., NISHINAKA, Y., YODOI, J., FERRIERO, D.M., EPSTEIN, C.J. and HUANG, T.T. (2005). Selective neuronal vulnerability and inadequate stress response in superoxide dismutase mutant mice. Free Radic Biol Med 38: 817-828.

MARTIN, F.M., BYDLON, G. and FRIEDMAN, J.S. (2006). SOD2-deficiency sideroblastic anemia and red blood cell oxidative stress. Antioxid Redox Signal8: 1217-1425.

MELOV, S., SCHNEIDER, J.A., DAY, B.J., HINERFELD, D., COSKUN, P., MIRRA, S.S., CRAPO, J.D. and WALLACE, D.C. (1998). Anovel neurological phenotype in mice lacking mitochondrial manganese superoxide dismutase. Nat Genet 18: 159-163.

MUNIM A, ASAYAMA K, DOBASHI K, SUZUKI K, KAWAOI A, KATO K. (1992). Immunohistochemical localization of superoxide dismutases in fetal and neonatal rat tissues. J Histochem Cytochem. 40(11):1705-1713.

MYATT, L. (2006). Placental adaptive responses and fetal programming. J Physiol 572: $25-30$.

ONG, M.M., WANG, A.S., LEOW, K.Y., KHOO, Y.M. and BOELSTERLI, U.A. (2006). Nimesulide-induced hepatic mitochondrial injury in heterozygous Sod2(+/-) mice. Free Radic Biol Med 40: 420-429.

ORNOY, A. (2007). Embryonic oxidative stress as a mechanism of teratogenesis with special emphasis on diabetic embryopathy. Reprod Toxicol 24: 31-41.

PADMANABHAN, R. (2006). Etiology, pathogenesis and prevention of neural tube defects. Congenit Anom (Kyoto) 46: 55-67.

PELUFFO, H., ACARIN, L., FAIZ, M., CASTELLANO, B. and GONZALEZ, B. (2005) $\mathrm{Cu} / \mathrm{Zn}$ superoxide dismutase expression in the postnatal rat brain following an excitotoxic injury. J Neuroinflammation 2: 12.

PETROVIC, V., BUZADZIC, B., KORAC, A., VASILIJEVIC, A., JANKOVIC, A. and KORAC, B. (2006). Free radical equilibrium in interscapular brown adipose tissue: relationship between metabolic profile and antioxidative defense. Comp Biochem Physiol C Toxicol Pharmacol 142: 60-65.

QI, X., LEWIN, A.S., HAUSWIRTH, W.W. and GUY, J. (2003). Optic neuropathy induced by reductions in mitochondrial superoxide dismutase. Invest Ophthalmol Vis Sci 44: 1088-1096.

ROSSIGNOL, R., FAUSTIN, B., ROCHER, C., MALGAT, M., MAZAT, J.P. and LETELLIER, T. (2003). Mitochondrial threshold effects. Biochem J 370: 751-762.

SAMPER, E., NICHOLLS, D.G. and MELOV, S. (2003). Mitochondrial oxidative stress causes chromosomal instability of mouse embryonic fibroblasts. Aging Cell 2: 277-285

SHEPPARD, F.R., KELHER, M.R., MOORE, E.E., MCLAUGHLIN, N.J., BANERJEE, A. and SILLIMAN, C.C. (2005). Structural organization of the neutrophil NADPH oxidase: phosphorylation and translocation during priming and activation. $J$ Leukoc Biol 78: 1025-1042.

VALKO, M., LEIBFRITZ, D., MONCOL, J., CRONIN, M.T., MAZUR, M. and TELSER, J. (2007). Free radicals and antioxidants in normal physiological functions and human disease. Int J Biochem Cell Biol 39: 44-84.

XIA, X.G., ZHOU, H., SAMPER, E., MELOV, S. and XU, Z. (2006). Pol II-expressed shRNA knocks down Sod2 gene expression and causes phenotypes of the gene knockout in mice. PLoS Genet 2: e10.

YON, J.M., BAEK, I.J., LEE, S.R., JIN, Y., KIM, M.R., NAHM, S.S., KIM, J.S., AHN, B., LEE, B.J., YUN, Y.W. and NAM, S.Y. (2008a). The spatio-temporal expression pattern of cytoplasmic $\mathrm{Cu} / \mathrm{Zn}$ superoxide dismutase (SOD1) mRNA during mouse embryogenesis. J Mol Histol 39: 95-103.

YON, J.M., BAEK, I.J., LEE, S.R., KIM, M.R., LEE, B.J., YUN, Y.W. and NAM, S.Y. (2008b). Immunohistochemical identification and quantitative analysis of cytoplasmic Cu/Zn superoxide dismutase in mouse organogenesis. J Vet Sci 9: 233-240. 


\section{Further Related Reading, published previously in the Int. J. Dev. Biol.}

The influence of the intrauterine environment on human placental development Graham J. Burton, Eric Jauniaux and D. Stephen Charnock-Jones Int. J. Dev. Biol. (2010) 54: 303-311

Genetic control of morphogenesis - Hox induced organogenesis of the posterior spiracles James Castelli-Gair Hombría, María Luisa Rivas and Sol Sotillos Int. J. Dev. Biol. (2009) 53: 1349-1358

The spatio-temporal pattern of testis organogenesis in mammals - insights from the mole Francisco D. Carmona, Darío G. Lupiáñez, José-Ezequiel Martín, Miguel Burgos, Rafael Jiménez and Federico Zurita Int. J. Dev. Biol. (2009) 53: 1035-1044

Expression of complement components coincides with early patterning and organogenesis in Xenopus laevis Valérie A. McLin, Cheng-Hui Hu, Rina Shah and Milan Jamrich

Int. J. Dev. Biol. (2008) 52: 1123-1133

Apo-14 is required for digestive system organogenesis during fish embryogenesis and larval development Jian-Hong Xia, Jing-Xia Liu, Li Zhou, Zhi Li and Jian-Fang Gui

Int. J. Dev. Biol. (2008) 52: 1089-1098

A newly discovered oxidant defence system and its involvement in the development of Aurelia aurita (Scyphozoa, Cnidaria): reactive oxygen species and elemental iodine control medusa formation

Stefan Berking, Nicole Czech, Melanie Gerharz, Klaus Herrmann, Uwe Hoffmann, Hartmann Raifer, Guy Sekul, Barbara Siefker, Andrea Sommerei and Fritz Vedder

Int. J. Dev. Biol. (2005) 49: 969-976

On the etiopathogenesis and therapy of Down syndrome.

E Antila and T Westermarck

Int. J. Dev. Biol. (1989) 33: 183-188

5 yr ISI Impact Factor $(2009)=3.253$

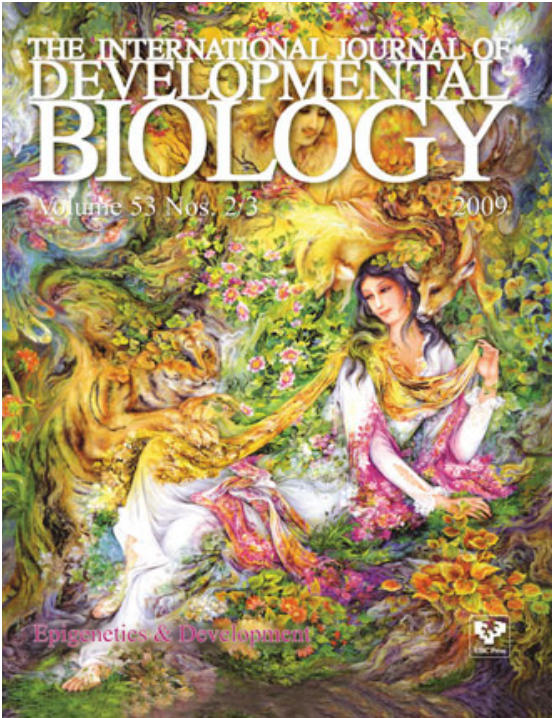

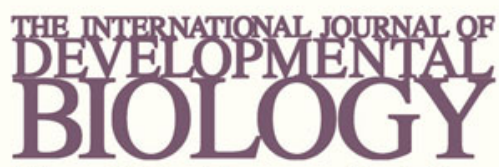

Volume 54 Nos. $6 / 7$
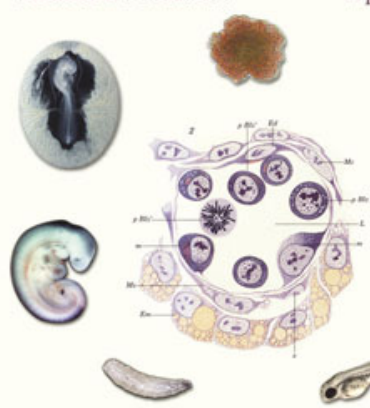

Developmental Hematopoiesis
Special Issue
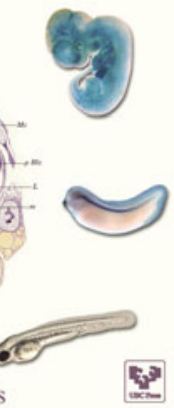

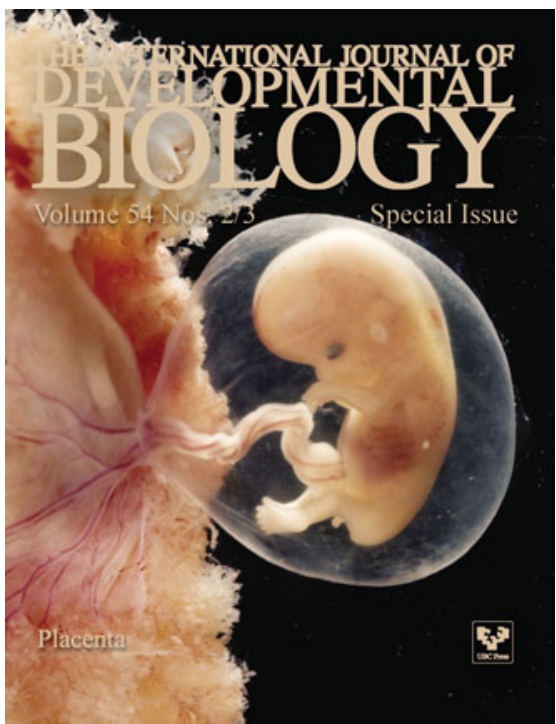

